Available online on 15.02.2020 at http://jddtonline.info
Open Access to Pharmaceutical and Medical Research
unrestricted non-commercial use, provided the original work is properly cited

Open $\odot$ Access

Research Article

\title{
In vivo antiplasmodial potential of Carrageenan and Prosopis africana buccal films of artemether on malariogenic mice
}

\author{
Petra Nnamani 1*, Ogechukwu Nnadi 1, Emmanuel Ibezim 1, Ebere Ayogu ${ }^{2}$, Joy Reginald-Opara 1, 3, Simon \\ Onoja ${ }^{4}$, Amelia Odo ${ }^{5}$, Agatha Ugwu ${ }^{1}$, Chidi Ogbonna ${ }^{6}$, Anthony Attama ${ }^{1}$ \\ ${ }^{1}$ Drug Delivery and Nanomedicines Research Group; Public Health and Environmental Sustainability Research Group; Department of \\ Pharmaceutics; Faculty of Pharmaceutical Sciences, University of Nigeria, Nsukka 410001, Enugu State, Nigeria; \\ 2 Department of Clinical Pharmacy and Hospital Administration; Faculty of Pharmaceutical Sciences, University of Nigeria, Nsukka 410001, \\ Enugu State, Nigeria; \\ ${ }^{3}$ School of Pharmacy, Faculty of Medical and Health Sciences, University of Auckland, Auckland, New Zealand \\ ${ }^{4}$ Department of Human Nutrition and Dietetics; University of Nigeria, Nsukka, Nigeria \\ ${ }^{5}$ Department of Human Kinetics and Health Education; University of Nigeria, Nsukka, Nigeria \\ ${ }^{6}$ Health Safety Environment and Quality Assurance, Compass Group Canada Ltd, 2710 - 17TH Avenue S.E., Calgary, Alberta, T2A0P6 Canada
}

\begin{abstract}
Objective: To deliver bioadhesive buccal films of artemether (ART) with ability to adhere, hydrate and release drug across the buccal membrane. Methods: Buccal films prepared by film casting using carrageenan (CAR) and Prosopis africana (PRO) were characterized by size, zeta potential, texture, water content, morphology, thermal and interaction studies, in vitro and in vivo antiplasmodial activity in mice. Results: Films were stable with sizes (2442 and $835 \mathrm{~nm}$ ), water content (21 and $15 \%)$, bioadhesivity (24 and $9.4 \%)$ and film thickness $(0.18$ and 0.28 $\mathrm{mm}$ ) for CARART and PROART respectively. Enthalpy of CARART, PROART and ART were 76, 22 and $88 \mathrm{~J} / \mathrm{g}$ where as parasitaemia reduc tion of 67 and $76 \%$ were observed for CARART and PROART respectively. Conclusion: Though CARART had better water content and bioadhesivity necessary for film hydration at buccal membrane, PROART eventually had superior buccal performance perhaps due to its film thickness and amorphous nanoparticle subdivision.
\end{abstract}

Key words: Artemether; Carrageenan; Prosopis africana; Sublingual buccal films; Malaria

Article Info: Received 10 Nov 2019; Review Completed 26 Dec 2019; Accepted 05 Jan 2020; Available online 15 Feb 2020

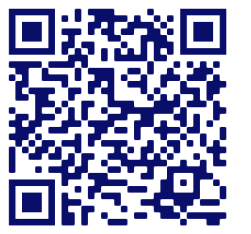

\section{Cite this article as:}

Nnamani P, Nnadi O, Ibezim E, Ayogu E, Reginald-Opara J, Onoja S, Odo A, Ugwu A, Ogbonna C, Attama A, In vivo antiplasmodial potential of Carrageenan and Prosopis africana buccal films of artemether on malariogenic mice, Journal of Drug Delivery and Therapeutics. 2020; 10(1-s):114-125 http://dx.doi.org/10.22270/jddt.v10i1-s.3790

Petra Nnamani, Drug Delivery and Nanomedicines Research Group; Public Health and Environmental Sustainability Research Group; Department of Pharmaceutics; Faculty of Pharmaceutical Sciences, University of Nigeria, Nsukka 410001, Enugu State, Nigeria; ORCID ID: Petra 0. Nnamani ID: http://orcid.org/0000-0001-9677-1288

\section{Author's Contribution:}

Petra 0. Nnamani: Proposed, designed and characterized the formulation in this article.

Nnadi, Ogechukwu H: This was my Master student who worked at formulation and studies in Nigeria.

Ibezim, Emmanuel C.: He was a co-supervisor for this master's work with me.

Ayogu, E. E., Reginald-Opara Joy N.; Onoja,U U. S, Odo, Amelia N, Ugwu, Agatha A., Ogbonna, J.D.N. and Ogbonna, Chidi C: These were colleagues who assisted in the work at different levels; drafted and proof-read the work.

Anthony A. Attama: Co-supervised this work and proof-read the manuscript. 


\section{INTRODUCTION}

There has been a paradigm shift from conventional drug delivery systems (injections and orals) to alternative systems based on versatile novel drug delivery systems (NDDS) 1-4. NDDS are capable of delivering drugs through mainly non-invasive routes with the aim to improve use convenience and compliance 5 . These systems exploit the mucosal surfaces of skin, nose and oral cavities while delivering drugs through different carrier systems ${ }^{6}$. By implication, delivery systems such as topicals (gels, films, patches, creams etc), aerosols and other transdermal DDS not limited to the oral cavity (sublingual, oesophageal, and buccal systems) apply. Buccal delivery systems (BDS) may include disks, tablets, patches, liquids and semi-solids ${ }^{7-10}$ but among all, films and/or patches have shown greater preference ${ }^{8-11}$. These systems generally need to be bioand/or muco-adhesive to be able to withstand some obvious stresses due to their application sites, to be able to provide both local and/or systemic effects. For instance, due to the flushing action of saliva and/or food ingestion, BDS may suffer from frequent dosing, non-uniform absorption as well as dislodgement by the tongue ${ }^{10,12}$. Drug ionization could also occur for ionizable drugs due to $\mathrm{pH}$ of microenvironment thereby making the route impracticable for drugs with low $\mathrm{pKa}$ values since $\mathrm{pH}$ of the saliva is 6.5$6.913,14$. Therefore, to increase BDS residence contact time on mucosal membranes, hydrogel polymers (having numerous hydrogen bonding groups) could be used to provide bioadhesivity and flexibility ${ }^{11}, 14$. This would predispose BDS to proffer numerous advantages such as to bypass liver metabolism, avoid gastric irritation and enzymatic degradation in the gastrointestinal tract (GIT), provide local specificity and above all, improve use convenience and compliance ${ }^{15-17}$. Hence different local conditions of the oral cavity could easily be treated with BDS including oral ulcers, oral infections, dental caries, periodontitis, gingivitis etc ${ }^{14}$, as well as systemic administration of macromolecular agents such as peptides, proteins, and polysaccharides ${ }^{4,11}$.

Prosopis africana (PRO) polymer is obtained from the tropical plant Prosopis africana. Similar to k-carragenan (CAR), PRO is a generally regarded as safe (GRAS) polymer for different uses including extended release polymer ${ }^{18}$, bio/muco-adhesive systems ${ }^{19}, 20$; solubility enhancer ${ }^{21}$, plasticizer21, binder for tablets22, film/patches 21,23 , food supplement ${ }^{24-26}$, antimicrobial ${ }^{27}$, and water treatment ${ }^{28}$ etc. Prosopis gum is a natural polysaccharide consisting chiefly of glucose, fructose, galactose and xylose as the monosaccharide units, as determined by thin layer chromatography and complete acid hydrolysis analysis ${ }^{19}, 29$. The gum is made up of highly branched polysaccharides with chain structure formed when monosaccharides condense with the elimination of water molecule(s) ${ }^{19}$. The structural components of its rich amino acid constituents have been implicated in solubility enhancement properties through abundant hydrogen bonding groups ${ }^{21}$. It is a well-known biodegradable and biocompatible bioadhesive agent due to its anionic nature which aids more effective mucosal and/or tissue binding 18-20. Additionally, it is a sought-after food condiment for the Nigerian people due to its low toxicity. In the light of its bioadhesivity, low toxicity and cheap availability, it can be proposed as a delivery system for developing effective buccal adhesive films for treatment of some tropical disease such as malaria.

The antimalarial drug, artemether (ART) is a fast acting schizonticidal drug and the most effective of the artemissinin-combination therapies (ACT) for first-line treatment of malaria ${ }^{30}$. The challenge of drug resistance by Plasmodium parasite makes a short acting drug such as ART not to be useful as a monotherapyas conventionally obtainable, example in the capsule form (80-160 mg daily for 5 days) ${ }^{21}$. Instead, the fast-acting derivatives of artemissinin (artemether, dihydroartemisinin, arteether and artesunate) are combined with long acting antimalarials (lumenfantrine, amodiaquine, sulfadoxin-pyrimethamine, mefloquine, piperaquine) as ACTs, to deal with fast resolution of clinical symptoms as well as recrudescence ${ }^{31}$. Among all ACTs, artemether-lumenfantrine is the most widely used in different fixed oral (tablets) combinations (80/480, 40/240 and $20 / 120 \mathrm{mg}$ ) for treatment of uncomplicated falciparum malaria including multi-drug resistant ones ${ }^{21,} 31$. The large oral doses have attendant associated side effects (especially neurotoxicity) following twice daily dosing and rapid but incomplete absorption after oral administration with peak plasma concentrations reached about $2 \mathrm{~h}$ in addition to metabolism in the liver to the demethylated derivative, dihydroartemisinin (DHA) ${ }^{21}$. More so, it is rapidly eliminated with oral bioavailability after intramuscular injection approx. $43 \%$. Therefore, ART administration via the oral mucosa (buccal and sublingual) seems attractive due to its short action which could resolve its hepatic first-pass metabolism and degradation in the gastrointestinal tract, GIT14,32. This is hoped to exploit the rich blood supply $(20.3 \mathrm{~mL} / \mathrm{min} / 100 \mathrm{~g}$ tissue) available in the oral mucosa, the high surface area $\left(50.2 \mathrm{~cm}^{2}\right)$ as well as thin membrane (low thickness) 500 $600 \mu \mathrm{m}$ therein, to generally increase ART uptake ${ }^{14,33}$.

In the light of the above, we report here the development of solvent cast films for buccal delivery of artemether (ART). These drug films were produced with kCarrageenan (CAR) and Prosopis africana(PRO) as hydrogel polymers with the aid of propylene glycol (plasticizer), saccharine sodium (sweetner) and peppermint oil (flavourant); following optimizations of concentration (plasticizer, polymer, sweetner and flavor), drying time, temperature and functional properties of the final films. The resultant drug films (CARART and PROART) were characterized by thickness, drug content, folding endurance, morphology, weight variation, viscosity, degree of crystallinity and compatibility, in vitro drug release, ex vivo bioadhesivity and in vivo growth inhibition of plasmodium in malariogenic mice. To understand the particle make-up, carefully measured film size $\left(2 \mathrm{~cm}^{2}\right)$ was allowed to swell for $8 \mathrm{~h}$ in milliQ-water $(5 \mathrm{ml})$ of $\mathrm{pH} 6.8$ and the aqueous dispersion was checked for size (Z-ave), polydispersity index and zeta potential. All these were done to provide proof as to hope for effective BDS of ART which could improve use convenience and compliance to reduce development of resistance as well as an alternative low dose regimen to oral large-dosed tablets.

\section{MATERIALS AND METHODS}

\subsection{Materials}

Artemether was a gift from Ipca Laboratories Ltd. India. Other ingredients include k-carrageenan and absolute ethanol, (Sigma Aldrich, Germany), propylene glycol, sodium saccharine andpeppermint oil (Merck, Germany). All other reagents and solvents were analytical grade and were used as procured.

\subsection{Preparation of Prosopis polymer}

Prosopis seed was procured from Orba market, Udenu Local Government Area of Enugu State, Nigeria. Prosopis africana peel powder (PAPP) was prepared according to earlier methods ${ }^{18}, 28,34$, with slight modifications. Briefly, Prosopis seeds were boiled overnight. After the inner fermentable seed (soup flavorant in Nigeria) was separated from the peels, there was further separation 
of the peel into two parts: 1) fleshy white mesocarp (gum containing portion) and, 2) hard pericarp (outermost part). The white mesocarp (gum) was washed (thrice) with deionized water, sun-dried to constant weight and ground into powder using laboratory grinding machine. The powder was sieved with a laboratory sieve of known mesh size to obtain fine powders used for this study.

\subsection{Formulation of films}

Prior to final preparations, all parameters including concentration (polymer, drug, plasticizer, sweetner and flavorant), stirring time and drying temperature were optimized. To determine the optimal drying time, equal amount of dispersion was poured into Petri dishes (diameter $3.4 \mathrm{~cm}^{2}$ ) and weighed every $24 \mathrm{~h}$ up to $72 \mathrm{~h}$ until a constant weight was achieved. An impermeable backing membrane/layer was prepared from ethanol (E), ethylcellulose (EC) and soy bean oil (SBO) to represent 4 and $10 \% \mathrm{w} / \mathrm{v}$ respectively of SBO and EC in absolute E. The mixture was stirred until homogeneous solution was obtained. This solution $(10 \mathrm{ml})$ was poured into Petri dish $(3.4 \mathrm{~cm})$ and dried in the oven at $30^{\circ} \mathrm{C}$ for $3 \mathrm{~h}$.

Aqueous solution of polymers (k-carragenaan (CAR) and Prosopis polymer (PRO)) were prepared by separately adding $1 \mathrm{~g}$ of CAR or PRO to $25 \mathrm{ml}$ of distilled water and stirring for $5 \mathrm{~min}$. Some $10 \mathrm{mg}$ of saccharine sodium (sweetner) was added to solution and stirred for $5 \mathrm{~min}$, before addition of propylene glycol $(10 \mathrm{ml})$ as plasticizer and stirring for another $1 \mathrm{~min}^{35}$. This was followed by the addition of $1 \mathrm{ml}$ of peppermint oil (flavourant) and final stirring for further $1 \mathrm{~min}$ to give solution A. For the blank films (without drug), the resultant solution A was cast into Petri dishes (diameter $3.4 \mathrm{~cm}$ ) containing the dried backing layers and covered with an inverted funnel for gradual drying at room temperature. For the drug-containing films, optimized concentration of $500 \mathrm{mg}$ of artemether (ART) was added into $5 \mathrm{ml}$ of absolute ethanol and stirred for $5 \mathrm{~min}$ to give solution B. Solution A was separately added into solutions $B$ and mixtures were stirred for $10 \mathrm{~min}$ before casting as earlier described. Triplicate formulations were made for each batch. After drying at room temperature, the films were stored in desiccators until used. Artemether films formulated with carrageenan were coded as CARART while those formulated with Prosopis africana were referred to as PROART.

\subsection{Physical evaluation of hydrogels}

Prior to casting, the hydrogel formulations were physically examined for color, homogeneity, and consistency. The $\mathrm{pH}$ was also re-evaluated (before each use) to make sure that it was stable within the salivary $\mathrm{pH}$ of 6.5-6.9.

\subsection{Morphology and texture analysis}

The morphology of the film samples was analyzed through scanning electron microscopy (SEM). The dry films were gold coated to about $5 \mu \mathrm{m}$ thickness using a coater unit under a high vacuum. SEM analysis of films (PROART and CARART) was performed on a Philips XL-30M scanning electron microscope instrument.

\subsection{Microenvironment $\mathrm{pH}$ and particle characterization}

The microenvironment $\mathrm{pH}$ of carefully measured film sizes $\left(2 \mathrm{~cm}^{2}\right)$ were determined to evaluate possible oral mucosal irritation. The films were allowed to swell for $8 \mathrm{~h}$ in milliQ-water of $\mathrm{pH} 6.8$ contained in small beakers. The $\mathrm{pH}$ of the aqueous dispersion was determined using a $\mathrm{pH}$ meter
(L1 127 Elico, India). Triplicate measurements were done per batch of formulation.

The mean diameter (Z-ave) and polydispersity index of the above aqueous dispersions obtained from CARART and PROART films were measured after appropriate dilutions using a Zetasizer Nano-ZS (Malvern Instruments, Worcester, UK) equipped with a $10 \mathrm{~mW} \mathrm{He}-\mathrm{Ne}$ laser employing the wavelength of $633 \mathrm{~nm}$ and a backscattering angle of $173^{\circ}$ at $25{ }^{\circ} \mathrm{C}$. All samples were diluted with sufficient milliQ-water to obtain a suitable scattering intensity, before photon correlation spectroscopic (PCS) analysis, and were then placed in a $10 \mathrm{~mm}$ diameter cell. Particle size analysis was performed using Mie theory.

The zeta potentials of the drug films were determined via electrophoretic mobility measurements using a Zetasizer Nano-ZS (Malvern Instruments, Worceshtire, UK). The zeta potential was calculated applying the Helmholtz-Smoluchowski equation $(n=3)$.

\subsection{Technological evaluation of the films}

The thickness of the film was measured with micrometer screw gauge (Mitutoyo, Kawasaki Japan). The measurement was taken at five different areas of the film; four around the edges and one in the center. The mean and standard deviation of the five measurements was calculated for each film. For weight variation, ten films from each of CARART and PROART batches were individually weighed. Variations in weight were determined after triplicate determination. The Folding endurance (FE) of the formulated films were determined by repeatedly folding the films of uniform cross-sectional area $\left(4 \times 4 \mathrm{~cm}^{2}\right)$ and thickness, at the same place until it broke. The number of times each film was folded at the same place without breaking gave the value of FE. Triplicate determinations were done for validity of statistical result.

\subsection{Bioadhesive evaluation of the films}

The bioadhesive property of the formulated films were determined using a texture analyzer (TA.XT2, Stable Micro System, UK) and fresh chicken pouch as a model tissue as previously described 36 with slight modification. The calculated work of adhesion was used as a measure of the bioadhesive property of the films.

\subsection{Differential scanning calorimeter (DSC)}

DSC experiments (TA Instrument, USA) were performed to detect the phase transition of the pure compounds and their mixtures as well as investigate any possible interaction between the initial compounds used to prepare the films. To investigate the transition of drug molecule from crystalline to amorphous form during the formulation process, sufficient quantity of PROART and CARART films enough to contain at least 3-5 mg of ART was weighed in aluminum pans, heated from 25 to $150{ }^{\circ} \mathrm{C}$ at 10 $\mathrm{C} / \mathrm{min}$ under constant flushing with nitrogen $(10 \mathrm{ml} / \mathrm{min})$. The DSC parameters, such as temperature onset, maximum peak, and enthalpy were generated.

\subsection{Fourier transform infrared spectroscopy(FT-IR)}

FT-IR study was carried out using BIO-RAD FT-IR 3000 (BIORADCompany, USA). The FT-IR spectra of PROART and CARART buccal films, ART, PRO and CAR polymers were obtained using $\mathrm{KBr}$ discs in the region of $4000-500 \mathrm{~cm}^{-1}$.

\subsection{Thermogravimetic analysis (TGA)}

TGA was used to measure the water content within the film. Samples weighing between 3 and $10 \mathrm{mg}$ were packed into aluminum pan and placed in a tarred balance of a high- 
resolution TG 2950 instrument (Crawley, UK). The TGA was programmed to heat the sample from 25 to $150{ }^{\circ} \mathrm{C}$ at the rate of $10{ }^{\circ} \mathrm{C} / \mathrm{min}$. The weight loss was noted and used to calculate the water content of the films.

\subsection{Drug content analysis}

Accurately weighed $100 \mathrm{mg}$ of drug film (CARART and/or PROART) was transferred to a $100 \mathrm{ml}$ volumetric flask and dissolved with $5 \mathrm{ml}$ of ethanol. To it, $25 \mathrm{ml}$ of $1 \mathrm{~N}$ $\mathrm{HCl}$ was added and heated using thermo-regulated water bath for $30 \mathrm{~min}$ at temperature of $80 \pm 2{ }^{\circ} \mathrm{C}$, slightly modified according to an earlier method 37 . The solution was allowed to cool at room temperature, filtered and the volume was made up to $100 \mathrm{ml}$ mark with deionized water and/or simulated salivary fluid, SSF ( $\mathrm{pH}$ 6.5). This was scanned in a UV/VIS spectrophotometer (Spectrumlab 752s, UK) at 254 $\mathrm{nm}$ and the amount of drug was calculated reference to a Beer's plot.

\subsection{Dissolution rate studies and drug release kinetics}

Drug dissolution studies were determined using magnetic stirrer method. Some $50 \mathrm{ml}$ of two different dissolution media (deionized water and SSF, pH 6.5) contained in beakers were placed on magnetic stirrer hot plate at $37{ }^{\circ} \mathrm{C}$ with stirring speed of $100 \mathrm{rpm}$. A volume of 5 ml was withdrawn at initial 30 min interval then at hourly interval for $12 \mathrm{~h}$ while replacing each withdrawal with $5 \mathrm{ml}$ of fresh media. However, to each $5 \mathrm{ml}$ withdrawn sample at different time intervals, $0.5 \mathrm{ml}$ of ethanol and $2.5 \mathrm{ml}$ of $1 \mathrm{~N}$ $\mathrm{HCl}$ were added and heated for $25 \mathrm{~min}$ in a water bath at $80 \pm 2{ }^{\circ} \mathrm{C}$, cooled, filtered and diluted to $10 \mathrm{ml}$ with the medium before UV/VIS measurement (Spectrumlab 752s, $\mathrm{UK})$ at $254 \mathrm{~nm}$.

Different release models ${ }^{37}$ were applied to study the kinetics and mechanisms of ART release from mucoadhesive films including zero order, first order, Higuchi and KorsmeyerPeppas models. First order assessed log cumulative of \% drug remaining versus time whereas zero order was done by fitting cumulative $\%$ drug release versus time ${ }^{38}$. The cumulative \% drug release versus square root of time described Higuchi model, whereas Ritger-Peppas and Korsmeyer-Peppas models assessed both Fickian and nonFickian release of drug from swelling as well as non-swelling systems by $\log (M t / M \propto)=\log k+n \log t$. The best fit model depended on the linearity of the plots as represented by the $\mathrm{R}^{2}$ values ${ }^{37}$.

\subsection{Ex vivo buccoadhesivity of films on bovine buccal membrane}

Bovine buccal mucosa was collected from freshly slaughtered cow from Ogige market abattoir, Nsukka (Nigeria) and frozen until used. The mucin lining of the buccal membrane was gently scraped off with spatula leaving a thin membrane which was spread on Teflon block and wrapped with aluminum foil before storing in the freezer. Prior to use, it was thawed in saline solution at ambient temperature.

The biological membrane was fixed on a non-absorbable surface then pinned with dissecting pins to prevent the tissue from slipping off. The film was attached to the ring of the Du Nouy tensiometer with cyanoacrylate adhesive and lowered to make contact ( $5 \mathrm{~min}$ ) with the tissue membrane on the platform ${ }^{39}$. The ring with the film was gradually raised at the rate of $1 \mathrm{~mm} / \mathrm{min}$. The force $(\mathrm{g})$ was taken at equal intervals until the film was completely detached from the tissue membrane. Film contact time with the intestine was 5 min in each determination and a curve was traced between contact time (min) and force (g) whereby the work of adhesion $(\mathrm{g} / \mathrm{cm})$ was equal to the area under the curve. Triplicate determinations were taken for each film batch.

\subsection{In vivo schizontocidal activity}

The animal experimental protocols were in accordance with the guidelines for conducting animal experiments stipulated by our Institution's Animal Ethics Committee $^{40}$ and in compliance with the Federation of European Laboratory Animal Science Association and the European Community Council Directive of November 24, 1986 (86/609/EEC). Briefly, the mice were divided into four groups of five mice each.

Evaluation of the curative effect of formulated films against established plasmodium infection was carried out ${ }^{37}$. On the day 0 of the test, percentage parasitemia and red blood cell count of the donor mice was determined by a Giemsa-stained thin blood smear of the donor mice and improved Neubauer counting chamber respectively. Blood of the donor mice was collected by cardiac puncture and diluted with physiological saline (normal saline) to $10^{8}$ parasitized erythrocytes per $\mathrm{ml}$ (i. e. $0.2 \mathrm{ml}$ of $10^{8}$ parasitized erythrocyte $/ \mathrm{ml}$ ), which was injected intra-peritoneally into each of the experimental mice in Fig. 1 (image A, B). Thirty mice were all inoculated with chloroquine-sensitive strain of Plasmodium berghei berghei (NK 65) and left untreated until the fourth day $\left(D_{4}\right)$ post inoculation. The mice were weighed and randomized into six groups of five mice each. Post inoculation (day 4), Group A (negative control) was administered with $1 \mathrm{ml} / \mathrm{kg}$ of distilled water, group $\mathrm{B}$ (positive control) received $5 \mathrm{mg} / \mathrm{kg}$ body weight equivalent to $12 . .5 \mathrm{mg}$ of ART oral tablet dispersed in $1 \mathrm{ml}$ of distilled water. Groups C and D received uniform doses of ART ( $5 \mathrm{mg}$ ) contained in drug film of CARART (11.4 mg) and PROART $(12.4 \mathrm{mg})$ which were carefully stocked to the palates of the mice (image $C)$. On day-7 $\left(D_{7}\right)$, each mouse was tail-bled (image D) and a thin blood film was made on a microscope slide. The films were stained with $10 \%$ Giemsa solution and examined microscopically to monitor the parasitaemia level. The antimalarial activity was determined by the equation:

$$
\left.\% \text { Activity }=\frac{\text { Mean parasitaemia in treated group }}{\text { Mean parasitaemia in control group }} \times 100 \quad . .1\right)
$$




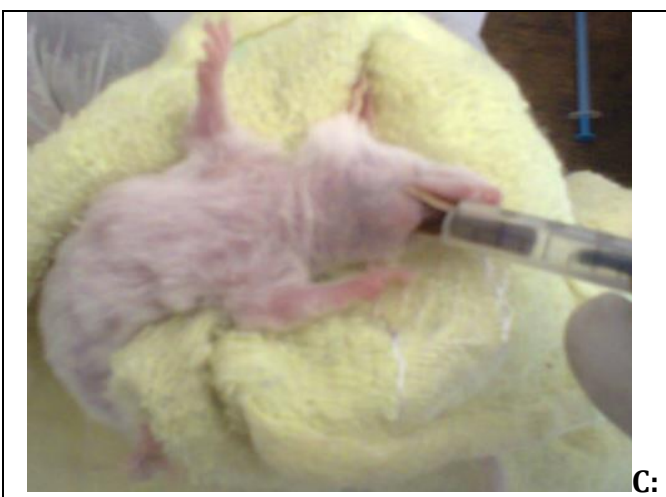

Placement of drug film into the buccal cavity

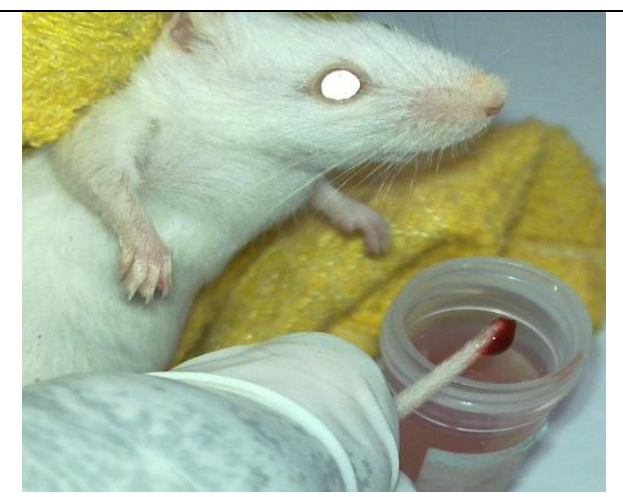

D: Collection of blood after treatment

Fig. 1: Preparation and treatment of malariogenic mice

\subsection{Statistical analysis}

All the data generated were expressed as mean \pm standard deviation. For group comparisons, one-way ANOVA with duplication was applied. Statistical significance was determined using student $\mathrm{t}$-test, with $\mathrm{P}<0.05$ considered to be statistically significant.

\section{RESULTS}

\subsection{Physical evaluation of hydrogels}

To increase residence, contact time of the films on mucosal membranes, hydrogel polymers (PRO and CAR), having numerous hydrogen bonding groups were used to provide bioadhesivity and flexibility 11,14 . The PROART hydrogel formulated was homogenous, partially transparent and fairly viscous, while the PROART film was moderately transparent. The CARART hydrogel was homogenous, transparent and less viscous than PROART, while the CARART film was very transparent. CARART films were therefore lighter than PROART films as well as had more uniform measurements. Hydrogel particles were spherical but not so in dry films.

\subsection{Morphology and texture analysis}

Scanning electron microscopic (SEM) analysis was adopted to investigate the surface characteristics and internal structure of the formulated artemether-loaded films (CARART and PROART). Single particles of the polymers CAR (A-C), PRO (J-L) and ART (M-O) in (Fig. 2) appeared more cuboid while ART-films CARART (D-F) and PROART (G-I) were of different shapes. The shape of drug carriers have been reported to be dependent on the purity of the carriers used $^{41}$ and particles prepared from highly pure lipids/carriers are usually more cuboid in nature ${ }^{42,21}$. PRO and CAR have high polydispersity indices $(>0.8)$ in Table 1 , showing they are chemically polydispersed as well as highly pure. Even though expected that only spherical particles would be present in all formulations, it should also be realized that the polymorphic nature of the carriers (data in brief) could determine the shape of particles. So that particles which existed in the stable $\beta$-modification could assume anisometric shapes, whereas those that existed in the metastable $\alpha$-polymorphic forms could appear spherical in nature 43,44 . This agreed with literature as the particle shape making up the drug films could be spherical ${ }^{45}$ and/or non-spherical 21 .

SEM images of the film surface and internal matrix are shown in Fig. 2 (A to O). The blank polymer films of CAR (images A-C) and PRO (images J-L) had uniform smooth appearance compared to the CARART (images D-F) and PROART (images G-I) films which in turn appeared uniform but slightly rough. However, with closer look into the internal structure, there appeared to be a higher, though irregular distribution of the ART within the film matrices (CARART) and (PROART). The internal structure of the PROART film (images G-I) showed more uniform distribution of irregularly shaped ART within the film matrix compared to CARART films (D-F) which had needle-like and/or rice-like particle clusters. This suggests that PROART film may have higher capacity for drug loading and retention, with fewer tendencies for drug expulsion to the film surface, than the CARART films. However, subsequent results would provide further proof on this.

Table 1: Properties of formulation

\begin{tabular}{|c|c|c|c|c|c|c|c|c|c|}
\hline Batch & $\begin{array}{c}\text { Z-Ave } \\
\text { (d. } \\
\text { nm) }\end{array}$ & PDI & $\begin{array}{c}\mathrm{ZP} \\
(\mathrm{mV})\end{array}$ & $\begin{array}{l}\text { Thickness } \\
(\mathrm{mm}) \pm \text { SD }\end{array}$ & $\begin{array}{c}\text { Bioadhesive } \\
\text { activity } \\
\text { (g/mm) }\end{array}$ & $\begin{array}{c}\text { Equilibrium } \\
\text { Water } \\
\text { content } \\
(\%)\end{array}$ & $\begin{array}{l}\text { Ex-Vivo } \\
\text { Bucco } \\
\text { Adhes. } \\
\text { Strength } \pm \\
\text { SD }\end{array}$ & $\begin{array}{l}\text { Melting } \\
\text { peak } \\
\left({ }^{\circ} \mathrm{C}\right)\end{array}$ & $\begin{array}{c}\text { Enthalpy } \\
(\mathrm{J} / \mathrm{g})\end{array}$ \\
\hline ART & - & - & - & - & - & $1.70 \pm 0.01$ & - & 86.96 & 87.51 \\
\hline CARART & 2442.0 & 1.00 & -64.4 & $0.18 \pm 0.02$ & $23.76 \pm 1.12$ & $21.40 \pm 0.08$ & $38 \pm 1.01$ & 207.05 & 76.02 \\
\hline PROART & 853.2 & 0.62 & -10 & $0.28 \pm 0.04$ & $9.38 \pm 0.58$ & $15.02 \pm 0.67$ & $30 \pm 1.21$ & 186.25 & 21.63 \\
\hline CAR & 568.50 & 0.80 & -50.5 & $0.08 \pm 0.01$ & $19.24 \pm 0.11$ & $18.00 \pm 0.06$ & $25 \pm 0.90$ & 242.05 & -3.16 \\
\hline PRO & 798.9 & 0.92 & -9.6 & $0.19 \pm 0.01$ & $17.24 \pm 0.81$ & $10.14 \pm 0.06$ & $21 \pm 0.78$ & 312.55 & -0.79 \\
\hline
\end{tabular}

Legends: Because the films had low water contents compared to pro-hydrogel state, the term equilibrium water content has been chosen. 

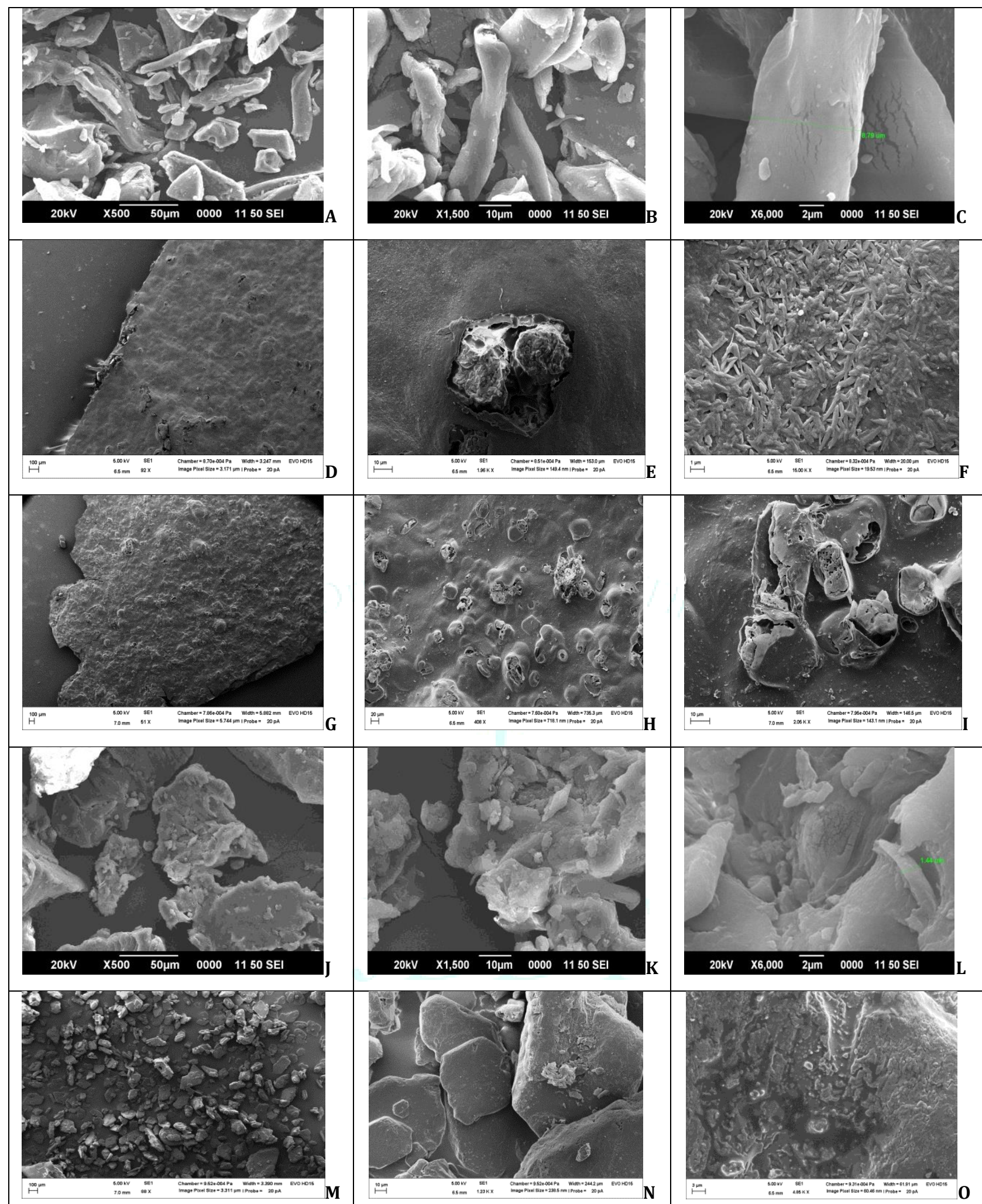

Fig. 2: Morphology and internal structure of drug films and polymers.

Legends: Surface, internal structure and enlarged internal structure of k-carrageenan, CAR (A-C); drug film, CARART (D-F); drug film, PROART (G-I); Prosopis africana polymer, PRO (J-L) and drug, ART (M-O) respectively.

\subsection{Microenvironment $\mathrm{pH}$ and particle characterization}

The microenvironment of the films had the required $\mathrm{pH}$ within the range for saliva (6.5-6.9). This shows that the formulation would likely not irritate the buccal mucosa. Particle size characterization of the pure polymers (CAR and PRO) were 568.5 and $798.9 \mathrm{~nm}$ respectively whereas their drug films (CARART and PROART) were 2442 and $853 \mathrm{~nm}$ respectively (Table 1). This implies that PROART films had better particle subdivision in the nanometer region than the CARART. This agrees with the observation in morphology and internal structure. 


\subsection{Technological evaluation of the films}

The thickness of the blank films produced from pure polymers of PRO and CAR were 0.19 and $0.08 \mathrm{~mm}$ whereas their ART-loaded counterparts (PROART and CARART) were 0.28 and $0.18 \mathrm{~mm}$ respectively. These values were within normal ranges reported for drug films in literature 46 . This shows that the PRO and/or PROART films were generally thicker than those of CAR and/or CARART.

\subsection{Bioadhesive evaluation of the films}

Bioadhesive determination revealed that work of adhesion varied depending on the polymer used. Table 1 generally shows that CARART films had higher work of adhesion (24 $\mathrm{g} / \mathrm{mm})$ than PROART films $(9 \mathrm{~g} / \mathrm{mm})$, similar to the pure polymers (CAR, 19 and PRO, $17 \mathrm{~g} / \mathrm{mm}$ ).

\subsection{Thermogravimetric analysis (TGA)}

TGA result showed that water content within the films was dependent on the polymer used (Table 1). Films produced from CAR and/or CARART had higher equilvalent water contents of 18 and $21 \%$ respectively than those of PRO and/or PROART (10 and $15 \%$ ) respectively. The drug (ART) had a much lower equilibrium water content of $1.70 \%$, which agreed with an earlier study ${ }^{21}$.

\subsection{Differential scanning calorimetry (DSC)}

Enthalpy values of ART, CAR, PRO, CARART and PROART were $87.51,-3.16,-0.79,76.02$ and $21.63 \mathrm{~J} / \mathrm{g}$ respectively (Table 1). This implies that the order of decreasing crystallinity was $\mathrm{ART}<\mathrm{CARART}<\mathrm{PROART}<\mathrm{CAR}<\mathrm{PRO}$; implying that the polymer (PRO) and the film (PROART) were the least crystalline. In other words, PRO was the most amorphous and its drug film (PROART) was also more amorphous than CARART; which by extrapolation implied that it was a better system to entrap the very crystalline ART, than CAR.

\subsection{Infrared (FTIR) analysis}

To demonstrate that it was possible to incorporate ART into polymers, infrared spectra of free ART, ART-loaded films (CARART and PROART) were obtained alongside individual polymers and presented. The bands at $3772,3294,2970$, $2206,1975,1712,1280,1118$ and $864 \mathrm{~cm}^{-1}$ were due to the vibration of the functional groups $\left(-\mathrm{OH}, \mathrm{C}-\mathrm{H}, \mathrm{CH}_{3}, \mathrm{C}=\mathrm{O}\right.$ and $=\mathrm{C}-\mathrm{H}$ out of plane bending vibration of aromatics \& enes) present in the structure of ART and can be seen in the spectra of the free ART, CARART, and PROART films. Spectra from films containing no ART did not show these peaks, indicating successful incorporation of ART into the buccal film formulations. Briefly, the band $3200-3400 \mathrm{~cm}^{-1}$ as seen in CAR, more pronounced than in PRO represent normal 'polymeric' $\mathrm{OH}$ stretch, which can be broad stretching to 3570-3200 $\mathrm{cm}^{-1}$ in PRO. The OH stretching vibration (broad or not) were seen in the bands of 3400-3611 in CARAT; $3570-3200 \mathrm{~cm}^{-1}$ in PROART and 3570-3200 $\mathrm{cm}^{-1}$ (H-bonded $\mathrm{OH}$ group) in PRO. Other prominent points of interaction were at $1900 \mathrm{~cm}^{-1}$ between CARART and ART due to aromaticity. PROART and ART had more prominent points of interaction at 2400, 1650-1590 (primary amine $\mathrm{NH}$ bend from PRO) and $1680-1620 \mathrm{~cm}^{-1}$ due to aromaticity $(\mathrm{C}=\mathrm{C})^{37}$.

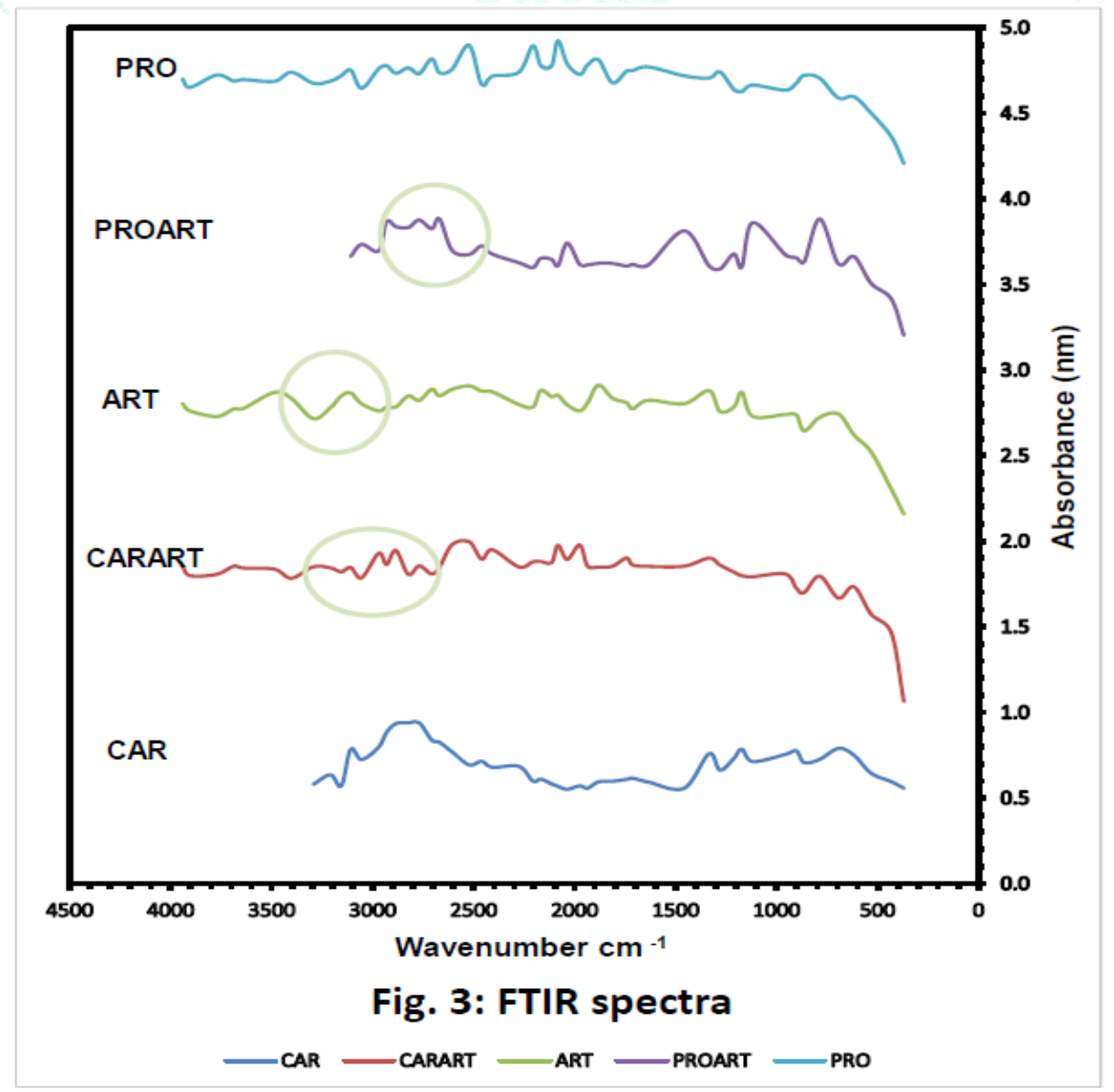

Legends: $3200-3400 \mathrm{~cm}^{-1}$ as seen in CAR, more pronounced than in PRO represent normal 'polymeric' OH stretch, it can be broad stretching to $3570-3200 \mathrm{~cm}-1$ which is more pronounced in PRO. The $\mathrm{OH}$ stretching vibration (broad or not) can been seen in the bands of 3400-3611 in CARAT, 3570-3200 cm-1 in PROART and 3570-3200 $\mathrm{cm}^{-1}$ (H-bonded OH group). Other prominent points of interaction are at $1900 \mathrm{~cm}^{-1}$ between CARART and ART due to aromaticity. PROART and ART have more prominent points of interaction at 2400 , 1650-1590 (primary amine NH bend from PRO) and 1680-1620 $\mathrm{cm}^{-1}$ due to aromaticity (C=C). 


\subsection{Dissolution studies}

The dissolution experiment utilized two different media: deionized water and simulated salivary fluid $(\mathrm{pH}$ 6.5). It was observed that in deionized water, ART release from CARART films was $6.8 \%$ after $4 \mathrm{~h}$ whereas PROART released $11.8 \%$ of ART at the same time; whereas in SSF, ART release from CARART films was $8.89 \%$ and PROART was $16.18 \%$ at the same time. The high initial release of artemether observed in all the formulations may be caused by un-encapsulated drug and a little burst release of artemether at the periphery of drug films. This perhaps, may be due to the fact that ARTloaded films of CARART and PROART generally had high particle sizes ( 2442 and $853 \mathrm{~nm}$ ) respectively. Earlier works had highlighted that lower particle sizes increased drug release via increased surface area ${ }^{47-49}$. Therefore, since the drug films composed of high particle sizes, drug release was poor due to decreased surface area. More so, high polydispersity presents non-uniformity in release as different shapes and sizes of particles are involved.

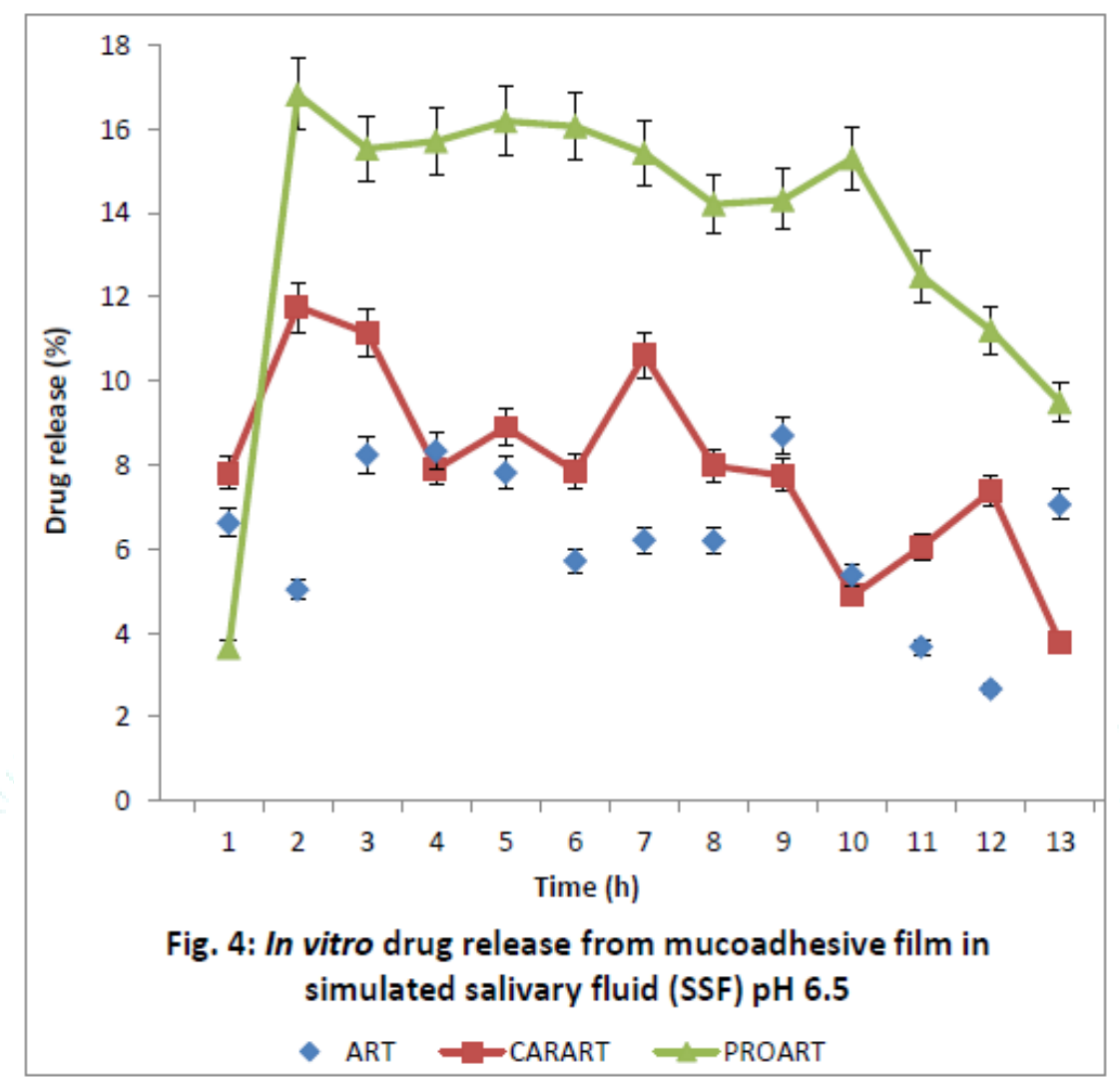

Legend: Fast initial release was more pronounced in PROART than CARART but PROART release-curve was more sustained and preferrable with less undulation $(n=3)$.

Table 2: Kinetics of ART release from buccal films

\begin{tabular}{ccccccc}
\hline Drug & Media & Batches & $\begin{array}{c}\text { Zero order } \\
\left(\mathbf{R}^{2} \mathbf{)}\right.\end{array}$ & $\begin{array}{c}\text { First order } \\
\left(\mathbf{R}^{2}\right)\end{array}$ & $\begin{array}{c}\text { Higuchi } \\
\mathbf{( \mathbf { R } ^ { 2 } )}\end{array}$ & $\begin{array}{c}\text { Korsmeyer-Peppas } \\
\text { Parameters }\left(\mathbf{R}^{2}\right)\end{array}$ \\
\hline \multirow{3}{*}{ ART } & $\begin{array}{c}\text { Deionized } \\
\text { water }\end{array}$ & CARART & 0.571 & 0.571 & 0.377 & 0.447 \\
& PROART & - & - & - & - \\
\cline { 2 - 7 } & $\begin{array}{c}\text { Simulated } \\
\text { salivary fluid } \\
\text { (SSF) }\end{array}$ & CARART & 0.540 & 0.540 & - & 0.412 \\
& PROART & - & - & 0.377 & -
\end{tabular}

Legends: $\mathrm{R}^{2}$ values of the release models were generally low, perhaps due to complexity of the release whereas the theory of these kinetic models was based on simple defined release mechanisms and sometimes changing geometrics and structure of solid matrices. Hence, release of artemether could not be satisfactorily explained using the kinetic models

\subsection{Antiplasmodial activity of films}

The study showed a parasitemia reduction range of 146 48, $150-36$ and $131-21$ for CARART, PROART and ART (commercial oral tablet) respectively (Fig. 5). Therefore, mean parasitemia reduction was 67,76 and $84 \%$ for CARART, PROART films and ART respectively (Fig. 6). These formulations had statistically significant $(\mathrm{P}<0.05)$ antiplasmodial effects when compared to negative control group ( $\mathrm{S} . \mathrm{D}=0.5)$ that received distilled water all through. The result equally confirmed that PROART had better antiplasmodial effect than CARART films, in agreement with all the earlier observations. 


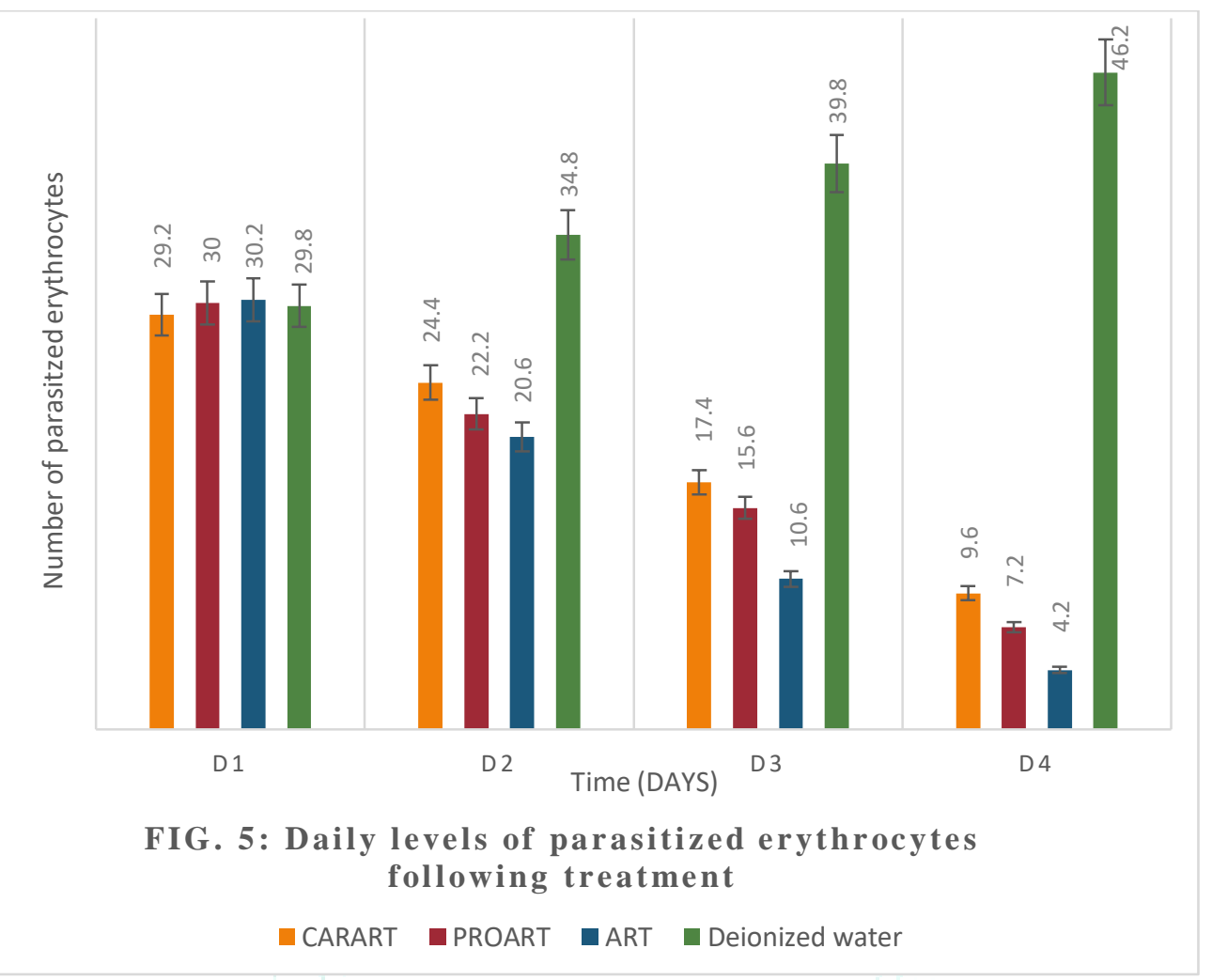

Legend: At day 1, the number of parasitized erythrocyte was nearly the same for all mice groups undergoing the treatment protocol. Subsequently at days $2-4$, the number of parasitized erythrocyte continuously increased daily in the mice group that received deionized water. There was also a continuous pattern of decrease most prominently in ART (4.2), PROART (7.2) and CARART (9.6). The polymer (PRO and CAR) therefore, could serve as delivery carriers for artemether, as films for buccal use in malariogenic mice (n=3).

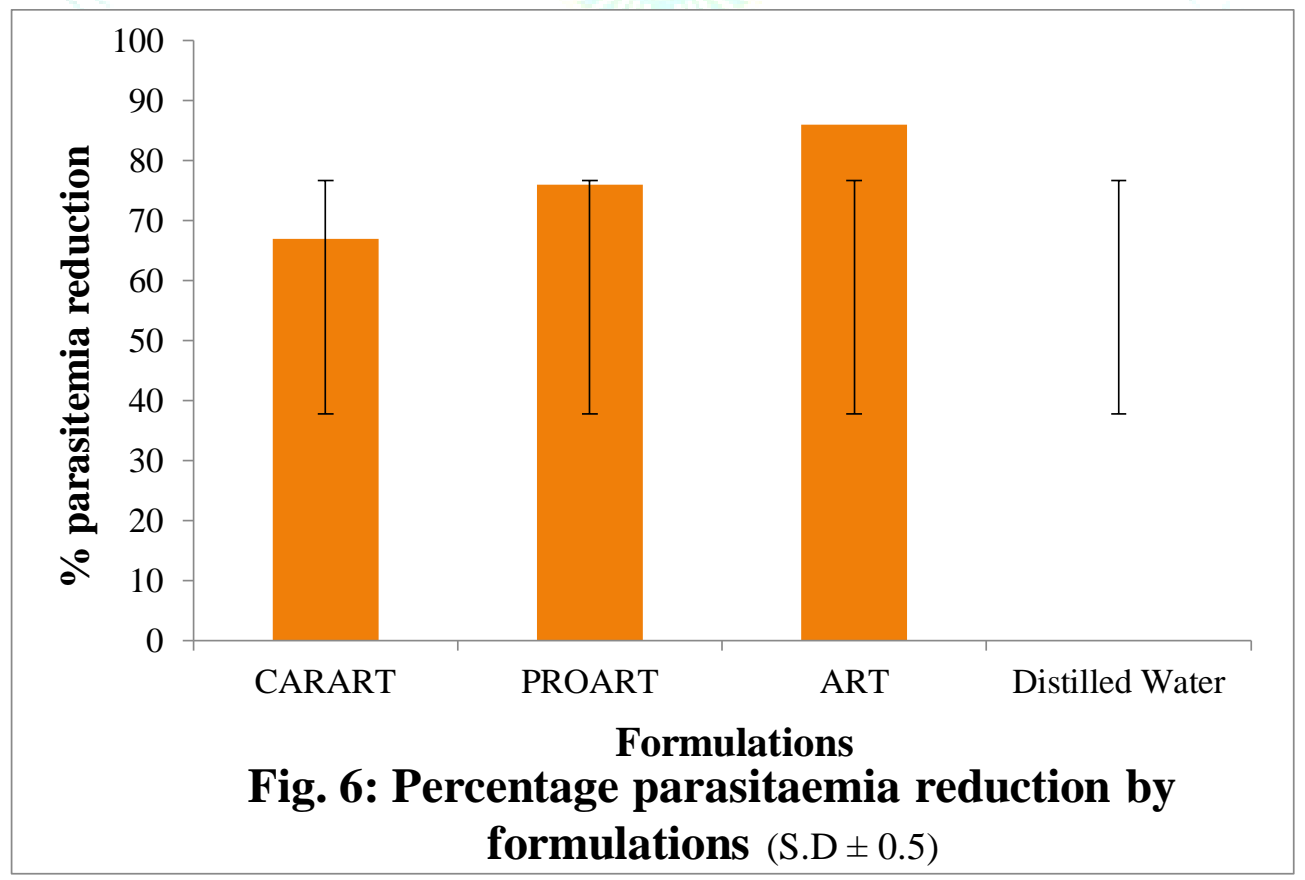

Legend: As shown earlier the mice that received water continously increased in number of parasitized erythrocyte without any reduction. On the contrary, the drug (ART) and drug films (PROART and CARART) showed good percentage reduction of parasitaemi a respectively as 86,76 and $67 \%$. Though ART tablet performed best, yet it was used as oral tablet without taste-masking whereas, drug films were sweetened with saccharine sodium and flavoured with mint oil, which could additionally improve acceptability $(n=3)$.

\section{DISCUSSION}

In the past and present, many companies utilize oral and intramuscular drug delivery technologies to develop artemether. Recent advancement pries into the delivery of drugs through buccal film formulation; hence in this study, sublingual administration has been chosen as a delivery route for possible systemic delivery of artemether.
Additionally, this approach is expected to improve patient compliance, since the extreme nausea-vomiting tendency of ART in the available conventional oral artemisinin combination therapies may be taken care of at once. The following results would provide proof as to hope for a sublingual ART regimen. 
The particle uniformity of PROART films showed better polydispersity index (0.6) than CARART (1.0) as well as the single polymers of CAR (0.8) and PRO (0.9). Zeta potential values for CAR $(-50.5 \mathrm{mV})$ and CARART $(-64 \mathrm{mV})$ were better than those of PRO $(-9.6 \mathrm{mV})$ and PROART $(-10 \mathrm{mV})$. This suggests that the films (loaded with ART or not) based on CAR would be more stable than those of PRO. More so, the CAR and/or CARART films were more transparent than the PRO and/or PROART ones; hence suggesting that the CAR and/or CARART films were more plastic and would most likely require more time for breaking the films than those of PRO and/or PROART. Subsequently, the folding endurance of the PROART film was 43 min whereas that of CARART film was $60 \mathrm{~min}$. This confirms that CARART films were lighter (more plastic) with more uniform measurement than PROART films. Additionally, CARART films would adhere more at mucosal surface to dissolve and release ART faster than PROART films. This agreed with both observations in thickness and folding endurance implying that CARART films adhered longer to the chicken pouch as a model tissue surface, than the PROART films. Since buccal films generally need to be bio- and/or muco-adhesive to be able to withstand some obvious stresses due to their application sites, in order to provide both local and/or systemic effects, it therefore follows that the CARART films were better adapted for bio-/muco-adhesion than the PROART films. This suggests that the flushing action of saliva and/or food ingestion would not affect CARART films as much as the PROART films; even though both may suffer from frequent dosing, non-uniform absorption as well as dislodgement by the tongue 10,32 . It was also observed that different films formulated with the same polymer had slight variation in water contents. Water molecules therefore, act as stabilizer to increase intermolecular spaces to allow polymeric chains to easily slide past each other ${ }^{50}$. This however affects stability, drug release and other physicochemical properties (elastic modulus) of the films formulated as would be established from the thermal analysis.

DSC is a measurement tool that gives insight into the thermal properties of ingredients and formulations in terms of melting point, enthalpy and glass transition temperature 18,21 , 51. Summarily, high enthalpy values suggest high crystallinity of systems and vice versa. In other words, when a system has high enthalpy value, it is therefore rigid (crystalline) without enough space to entrap anything. This could also explain why the particle sizes of PRO and PROART films were in the nanoparticle subdivision rather than CARART; which by extension despite the low mucosal adhesivity of PROART films, could indicate that PROART films may have more sustained release of ART in SSF (pH 6.5) than CARART.

Information obtained from FTIR measurement gives insight into the kind of interaction occurring due to the functional groups making up the systems. Fig. 3 shows the spectra of all measurements. The compatibility among the ART, polymers (CAR and PRO) and films (CARART and PROART) was studied. However, some new peaks were formed in both PROART (2083 $\left.\mathrm{cm}^{-1}\right)$ and CARART $(3402,2708,2461,2276$, 2036, 1813-1936, 1211 and $694 \mathrm{~cm}^{-1}$ ) due to intramolecular hydrogen bonding (O-H stretching vibration), aromatic, cyclic enes ( $\mathrm{v}=\mathrm{CH} \& \mathrm{Ar}-\mathrm{H})$, akly groups ( $\mathrm{vCH} 3), \mathrm{C}=\mathrm{O}$ groups $(\mathrm{vC}=\mathrm{O})$ and aromatics $\&$ enes $(=\mathrm{C}-\mathrm{H}$ out of plane bending vibration). These studies confirm that, structural components of polymers (CAR and PRO) responsible for their less crystallinity (according to DSC result) and perhaps dissolution enhancement may play vital role in establishing various interactions with drugs and consequently stabilize them thermodynamically.
Many earlier reports carried out on stabilization using different polymers suggest the significance of hydrogen bonding in stabilization of amorphous valdecoxib using PVP and HPC52; comparative study of stabilization efficiency of Gelucire 50/13 and PVP and investigation of mechanism involved 53 ; nanoporous silica xerogel, kaolin, and $\mathrm{Mg}-\mathrm{Al}-$ hydrocalcite involved in stabilization of amorphous nifedipine ${ }^{54}$, ibuprofen 55 , and celecoxib ${ }^{56}$ respectively. Polyvinyl pyrrolidone (PVP), hydroxypropyl cellulose (HPC), Gelucire and other carriers have been investigated to check their potential as stabilizer for amorphous form of drugs. PVP has been used to prevent devitrification of amorphous ketoconazole ${ }^{57}$. The mechanism of this stabilization is also traceable in the use of PRO and CAR to deliver ART as buccal films in this study. Alternatively, PRO has been proven to be a stabilizer for aceclofenac in addition to many other uses ${ }^{21}$.

Release from CARART films followed a manner that was more controlled than PROART films, even though both release was poor (Figure not shown). On the other hand, ART release in SSF ( $\mathrm{pH}$ 6.5) showed that CARART films achieved $11.76 \%$ release in $2 \mathrm{~h}$ whereas PROART released $16.82 \%$ in $2 \mathrm{~h}$ which was sustained till $10 \mathrm{~h}$ (Fig. 4). This suggests that for both fast and sustained release of ART, PROART films in SSF (pH 6.5) was the preferred formulation despite CARART films being more bioadhesive, stable $(-64 \mathrm{mV})$, transparent (thinner) and more plastic. Meanwhile, ART (87.51 J/g) existed in more amorphous form in the PROART films $(21.63$ $\mathrm{J} / \mathrm{g}$ ) than CARART films $(76.02 \mathrm{~J} / \mathrm{g}$ ); which therefore proves the enhanced dissolution and release of ART obtained from PROART films. Subsequently, the fine particle subdivision $(853 \mathrm{~nm})$ and double thickness advantage $(0.28 \mathrm{~mm})$ of PROART films as compared to the size (2442 nm) and thickness $(0.18 \mathrm{~mm})$ of CARART particles/films, could explain the sustained release of ART till the $10^{\text {th }}$ hour. However, the in vivo antiplasmodial activity would confirm these in vitro results. When the dissolution rate and pattern of the films were compared to the standard drug (pure ART), PROART in deionized water had dissolution pattern closer to it than CARART. The in vitro release was subjected to a kinetic analysis as shown in Table 2, for fitting into various models, such as zero-order, first-order, Higuchi, HixsonCrowell and Peppas exponential equation to ascertain the drug release. The plots were found linear, though release of ART from the films did not fit into any of the kinetic models. The plots generally had low $\mathrm{R}^{2}$ values. This behavior of the artemether films could be attributed to the complexity of the release, diffusion and permeation process, whereas the theory of these kinetic models was based on simple defined release mechanisms and sometimes changing geometrics and structure of solid matrices. Hence, release of artemether could not be satisfactorily explained using the kinetic models.

The result of ex-vivo buccoadhesive strength for ART buccal films are shown in Table 1 . Thus CARART films containing carrageenan polymer exhibited higher buccoadhesive strength (38) than PROART film (32) containing Prosopis africana polymer. This may be due to surface adhesion phenomenon as well as formation of secondary hydrogen bonds with mucosa as a result of rapid swelling of polymers involved. The single entities of the polymers (CAR and PRO) demonstrated similar trends as well.

The therapeutic effect of CARART and PROART were tested on mice infected with Plasmodium beighei (NK 65). Reduction in parasite count was investigated by comparing mean parasiteamia pre- and post- treatment from the different film formulations. Mean parasitemia reduction was 67, 76 and $84 \%$ for CARART, PROART films and ART respectively. These formulations had statistically significant 
$(\mathrm{P}<0.05)$ antiplasmodial effects when compared to negative control group $(S . D=0.5)$ that received distilled water all through. The result equally confirmed that PROART had better antiplasmodial effect than CARART films, in agreement with all the earlier observations such as fine particle subdivision $(853 \mathrm{~nm})$, double thickness advantage $(0.28 \mathrm{~mm})$ and sustained in vitro release of ART.

\section{CONCLUSION}

This study has demonstrated that natural polymers (CAR and PRO) can conveniently deliver ART as buccal films to treat malariogenic mice. The characteristics of the drug films more desirably favoured PROART than CARART films; hence better drug dissolution, release and antiplasmodial activity due to more uniform (0.6) amorphous $(21.63 \mathrm{~J} / \mathrm{g}$ ) nanoparticles (853 nm) make-up of PROART films which thickly (0.28 $\mathrm{mm}$ ), though porously and brittlely enclosed ART with lower equilibrium moisture content $(15 \%)$ for better stabilization $(-10 \mathrm{mV})$ through intramolecular hydrogen bonding of the ART and PRO molecules; than CARART films with higher equilibrium water content (21 \%) which increased intermolecular spaces allowing polymeric chains to easily slide past each other to expel entrapped ART. Overall, antiplasmodial efficacy was 86, 76 and $67 \%$ corresponding to ART $>$ PROART $>$ CARART respectively. Since all formulations achieved reduction in parasitaemia between 67 and $86 \%$, nonetheless, the improved ease of application and compliance, perhaps with elimination of vomiting and other gastrointestinal disturbances associated with conventional ART, could create hope for a clinical trial since antiplasmodial efficacy of the formulations were statistically significant.

\section{Acknowledgement}

The authors appreciate Prof. Dr. C. M. Lehr and group for particle characterization and SEM analysis.

\section{Conflict of interest}

Authors report no conflict of interest in the study carried out.

\section{REFERENCES}

1. Langer R. Transdermal drug delivery: past progress, current status and future prospects, Adv. Drug Dev Rev 2014; 56: 557 558.

2. Patel V.F., Liu F., Brown M.B. Advances in oral transmucosal drug delivery. J Control Rel 2011; 153: 106-16.

3. Morales J.O., McConville J.T. Manufacture and characterization of mucoadhesive buccal films. Eur J Pharm Biophar 2011; 77: 187-99

4. Park D-M., Song Y-K., Jee J-P., Kim H.T., Kim C-K. Development of chitosan-based ondansetron buccal delivery system for the treatment of emesis. Drug Dev Ind. Pharm 2012; 38: 10771083.

5. Mathias N.R., Hussain M.A. Non-invasive systemic drug delivery: Developabilityconsiderations for alternate routes of administration. J. Pharm. Sci. 2010; 99: 1-20.

6. Yehia S.A, El-Gazayerly O.N., Basalious E.B. Fluconazole mucoadhesive Buccal Films: In Vitro/In Vivo Performance. Curr. Drug Deliv. 2009; 6: 17-27 17.

7. Nishigaki M. Development of fast dissolving film containing dexamethasone as antiemetic medication: clinical medication. Int J Pharm 2012; 421: 12-17.

8. Meher J.G., Tarai M., Yadav N.P, Patnaik A., Mishra P., Yadav K.S. Development and characterization of cellulosepolymethacrylate mucoadhesive film for buccal delivery of carvedilol. Carbohydr Polym 2013; 96: 172-80.

9. Kumria R., Nair A.B., Al-Dhubiab B.E. Loratidine buccal films for allergic rhinitis: development and evaluation. Drug Dev Ind Pharm 2014a; 40: 625-31.

10. Kumria R., Nair A.B., Goomber G., Gupta S. Buccal films of prednisolone with enhanced bioavailability. Drug Deliv 2014b; $1-8$.
11. Guo R., Du X., Zhang R., Deng L., Dong A., Zhang J. Bioadhesive film formed from a novel organic-inorganic hybrid gel for transdermal drug delivery system. Eur. J. Pharm. Biopharm 2011; 7: 574-583.

12. Bruschi M.L., de Freitas O. Oral bioadhesive drug delivery systems. Drug Dev. Ind. Pharm 2005; 31: 293-310.

13. Castán H., Ruiz M.A., Clares B., Morales M.E. Design, development and characterization of buccal bioadhesive films of Doxepin for treatment of odontalgia. Drug Deliv, 2015; 2(6): 869-876.

14. Kianfar F., Chowdhry B.Z., Antonijevic M.D., Boateng J.S. Novel films for drug delivery via the buccal mucosa using model soluble and insoluble drugs. Drug Dev Ind. Pharm 2012; 38: 1207-1220.

15. Al-Dhubiab B.E., Nair A.B., Kumria R., Attimarad M., Harsha S. Development and evaluation of buccal films impregnated with selegiline-loaded nanospheres. Drug Deliv 2016; 23(7): 21542162.

16. Adhikari S.N., Nayak B.S., Nayak A.K., Mohanty B. Formulation and evaluation of buccal patches for delivery of atenolol. AAPS PharmSciTech 2010; 11: 1038-44.

17. Abdelbary G.A., Aburahma M.H. Oro-dental mucoadhesive proniosomal gel formulation loaded with lornoxicam for management of dental pain. J Liposome Res 2015; 25(2): 107 21. doi:10.3109/08982 104.2014.941861.

18. Nadaf S., Nnamani P.O., Jadhav N. Evaluation of Prosopis africana Seed Gum as an Extended Release Polymer for Tablet Formulation. AAPS PharmSciTech 2014 DOI: 10.1208/s12249-014-0256-y (Online ISSN: 1530-9932)

19. Adikwu M.U., Udeala O.K., Ohiri F.C. Physico-chemical properties of a new polysaccharide gum from Prosopis africana. Part II. Coacervation properties with ethanol. Discov. Inno 2000; 12: 80-84.

20. Attama A.A., Adikwu M.U., Okoli N.D. Studies on bioadhesive granules. I. Granules formulated with Prosopis africana (prosopis) gum. Chem. Pharm. Bull. 2000; 48:734-737.

21. Nnamani P.O., Lokhande C.D., Shinde A.J., Jadhav N.R., Sanandam M.R. Solid oral pharmaceutical composition. Nigeria Patent 2014; 565: September 30.

22. Emeje M., Izuka A., Isimi C., Ofoefule S., Kunle O. Preparation and standardization of a herbal agent for the therapeutic management of asthma. Pharm Dev Technol. 2011; 16: 170178.

23. Attama A.A., Nnamani P.O., Okorie O. Effect of $\mathrm{pH}$ and ionic strength on the bioadhesive properties of Prosopis africana gum. J. Pharm. Biores. 2005; 2: 141-145.

24. Barminas J.T., Maina H.M., Ali J. Nutrient content of Prosopis africana seeds Plant Foods for Human Nutri. 1998; 52: 325328.

25. Aremu M.O., Olonisakin A., Atolaye B.O., Ogbu C. Some nutritional and functional studies of Prosopis africana. Electron. J. Environ. Agric. Food Chem. 2006; 5: 1640-1648.

26. Adikwu M.U., Yoshikama Y., Takada K. Bioadhesive delivery of metformin using prosopis gum with antidiabetic potential, Biol. Pharm. Bull 2003; 26: 662-666.

27. Kolapo A.L., Okunade M.B., Adejumobi J.A., Ogundiya M.O. Phytochemical composition and antimicrobial A.L. activity of Prosopis africana against some selected oral pathogens. World J. Agric. Sci 2009; 5: 90-93.

28. Nnamani P.O., Kenechukwu F.C., Okonkwo C.C. and Otuu F.C. Performance of Prosopis Africana peel powder (PAPP) as a novel sorbent for remediating malachite green contaminated aqua system. Sci Res and Essays 2012; 7: 4130-4137

29. Adikwu M.U., Ezeabasili S.I., Esimone C.O. Evaluation of the physic-chemical properties of a new polysaccharide gum from Prosopis africana. Boll Chim Farm 2001; 140: 40-45.

30. Egunsola O., Oshikoya K.A. Comparative safety of artemetherlumefantrine and other artemisinin-based combinations in children: a systematic review. Malar J 2013; 12: 385.

31. WHO, 2014. World Malaria Report 2014. World Health Organisation.

32. Kumria R., Gupta V., Bansal S., Wadhwa J., Nair A.B. Oral buccoadhesive films of ondansetron: development and evaluation. Int J Pharm Investig 2013; 3: 12-8.

33. Sohi H., Ahuja A., Ahmad F.J., Khar R.K. Critical evaluation of permeation enhancers for oral mucosal drug delivery. Drug Dev. Ind. Pharm 2010; 36: 254-282. 
34. Nnamani P.O., Kenechukwu F.C. Okoye 0 and Akpa P.A Sustained release Mebendazole microcapsules prepared with Prosopis africana peel powder (PAPP) hydrogel. Indian J. Novel Drug deliv 2017; 9(3): 167-184.

35. Nnamani P.O., Attama A.A., Kenechukwu F.C., Ibezim E.C, Adikwu M.U. Pharmacodynamics of Piroxicam from Novel Solid Lipid Microparticles Formulated with Homolipids from Bos indicus. Curr Drug Deliv 2013; 10(6): 645-655.

36. Kianfar F., Ayensu I., Boateng JS. Development and physicomechanical characterization of carrageenan and poloxamer-based lyophilized matrix as a potential buccal drug delivery system. Drug Dev Ind Pharm 2013; 40: 361-9.

37. Nnamani P.O., Ugwu A.A., Ibezim E.C., Kenechukwu F.C., Akpa P.A., Ogbonna J.D.N., Obitte N.C., Lehr C.M., Attama A.A. Sustained-release Liquisolid Compact Tablets Containing Lumefantrine-Artemether as Alternate-Day-Regimen for Malaria Treatment to Improve Patient Compliance. Int. J. Nanomed 2016; 11: 6365-6378.

38. Nnamani P.O., Kenechukwu F.C., Dibua E.U., Ogbonna C.C., Monemeh U.L., Attama A.A. Transdermal microgels of gentamicin. Eur J Pharm Biopharm 2013; 84: 345-354.

39. Nnamani P.O., Hansen S., Windbergs M., Lehr C.M. Development of artemether-loaded nanostructured lipid carrier (NLC) formulation for topical application. Int. J. Pharm 2014; 477: 208-217.

40. Attama A.A. Kenechukwu F.C., Onuigbo E.B., Nnamani P.O., Obitte N., Finke J.H., Pretor S., Müller-Goymann C.C. Solid lipid nanoparticles encapsulating a fluorescent marker (coumarin 6) and antimalarials - artemether and lumefantrine: evaluation of cellular uptake and antimalarial activity. Eur J Nanomed 2016; 8(3): 129-138. ISSN (Online) 1662-596X, ISSN (Print) 1662-5986, DOI: 10.1515/ejnm-2016-0009.

41. Teeranachaideekul V., Souto E.B., Junyaprasert V.B., Müller R.H. Cetyl palmitate-based NLC for topical delivery of coenzyme Q10 - development, physicochemical characterization and in vitro release studies. Eur. J. Pharm. Biopharm 2007; 67: 141-148.

42. Westesen K., Siekmann B., Koch M.H.J. Investigations on the physical state of solid lipid nanoparticles by synchrom radiation X-ray diffraction. Int. J. Pharm 1993; 93: 189-199.

43. Souto E.B., Müller R.H. Investigation of the factors influencing the incorporation of clotrimazole in SLN and NLC prepared by hot high-pressure homogenization. J. Microencapsul 2006; 23: 377-388.

44. Schubert M.A., Müller-Goymann C.C. Characterization of surface-modified solid lipid nanoparticles (SLN): influence of lecithin and non-ionic emulsifier. Eur. J. Pharm. Biopharm 2005; 61: 77-86.

45. Saupe A., Wissing S.A., Lenk A., Schmidt C., Müller R.H. Solid lipid nanoparticles (SLN) and nanostructured lipid carriers
(NLC)-structural investigations on two different carrier systems. Biomed. Mater. Eng 2005; 15: 393-402.

46. Patel D.J., Pate J.K. Design and evaluation of famotidine mucoadhesive nanoparticles for aspirin induced ulcer treatment. Braz Arch Biol Technol 2013; 56(2): 223-36 doi:10.1590/s1516-89132013000 200007.

47. Akiyama Y., Yoshioka M., Horibe H., Hirai S., Kitamori N., Toguchi H. Novel oral controlled-release microspheres using polyglycerol esters of fatty acids. J. Control. Release 1993; 26: $1-10$.

48. Savolainen M., Khoo C., Glad H., Dahlqvist C., Juppo A.M. Evaluation of controlled release polar lipid microparticles. Int J. Pharm 2002; 244: 151-161.

49. Agubata C.O., Nzekwe I.T., Attama A.A., Mueller-Goymann C.C., Onunkwo G.C. Formulation, characterization and anti-malarial activity of homolipid-based artemether microparticles. Int J Pharm 2015; 478: 202-222.

50. Puglia C., Offerta A., Rizza L., Zingale G., Bonina F., Ronsisvalle S. Optimization of curcumin loaded lipid nanoparticles formulated using high shear homogenization (HSH) and ultrasonication (US) methods. J. Nanosci. Nanotechnol 2013; 13: 6888-6893.

51. Reginald-Opara J.N., Attama A.A., Ofokansi K.C., Umeyor C., Kenechukwu F.C. Molecular interaction between glimepiride and Soluplus1-PEG 4000 hybrid based solid dispersions: Characterisation and anti-diabetic studies. Int. J. Pharm 2015; 496: 741-750.

52. Jones E., Ojewole E., Pillay V., Kumar P., Rambharose S., Govender T. Monolayered multipolymeric buccal films with drug and polymers of opposing solubilities for ARV therapy: physico-mechanical evaluation and molecular mechanics modelling. Int J Pharm 2013; 455: 197-212.

53. Shimpi S.L., Mahadik K.R., Paradkar A.R. Study on mechanism for amorphous drug stabilization using Gelucire 50/13. Chem Pharm Bull 2009; 57: 937-942.

54. Palm T, Esfandiary R, Gandhi, R. The effect of PEGylation on the stability of small therapeutic proteins, Pharm. Dev. Technol 2011; 16: 441-448.

55. Subrata M., Satyanarayan P, Kalpana S, Pintu K.D., Arindam S., Gaurisankar G., Arijit M et al. Formation of physically stable amorphous phase of ibuprofen by solid state milling with kaolin. Eur J Pharm Biopharm 2008; 68: 346-51.

56. Giovino C, Ayensu I, Tetteh J, Boateng J.S. An integrated buccal system combining chitosan films impregnated with peptide loaded PEG-b_PLA nanoparticles. Colloids Surf B Biointerf 2013; 112: 9-15

57. Youssef A.M.K, Winter G. A critical evaluation of microcalorimetry as a predictive tool for long term stability of liquid protein formulations: Granulocyte Colony Stimulating Factor (GCSF). Eur J Pharm Biopharm 2013; 84: 145-155. 